\title{
Vortex study on a hydraulic model of Godar-e-Landar Dam and Hydropower Plant
}

\author{
R. Roshan ${ }^{1}$, H. Sarkardeh ${ }^{2}$ \& A. R. Zarrati ${ }^{3}$ \\ ${ }^{I}$ Water Research Institute, Iran \\ ${ }^{2}$ Department of Engineering, Tarbiat Moallem University of Sabzevar, \\ Iran \\ ${ }^{3}$ Department of Civil Engineering, Amirkabir University of Technology, \\ Iran
}

\begin{abstract}
In hydropower plants the kinetic energy of falling water is captured to generate electricity. In this process, the formation of vortices with an air core at the power intake entrances is expected at lower reservoir levels. The entrainment of air and swirl into the power tunnels leads to a reduction of power generation and vibration and damage to the turbine blades. To use the maximum potential of water power at lower reservoir levels when water is scarce, it is necessary to prevent vortex formation. Anti-vortex devices are usually considered as an efficient method for vortex prevention. The Godar-e-Landar Dam and Hydropower Plant is sited on the Karun River in the province of Khuzestan, Iran, with the capacity of $2000 \mathrm{MW}$. There are four horizontal power intakes where the capacity of each intake is equal to $375 \mathrm{~m}^{3} / \mathrm{s}$. The dam is a rock fill type with $170 \mathrm{~m}$ height from the foundation. The dam has a gated spillway with an ogee chute and stilling basin. In the present work a physical model was used to study the formation and prevention of air core vortices at power intakes of the dam. Studies showed that vortices form when the reservoir water level decreases from a certain elevation and air enters the power tunnels. The performance of anti-vortex walls was therefore examined to eliminate vortices or reduce their strength and prevent entrainment of air. The anti-vortex walls were constructed on top of each intake to increase the friction stresses within the vortex path. To distinguish the vortex type, light colorful objects were released in the flow. Results of experiments showed Type 4 vortices (which may be a stronger air core Type 6 in prototype) reduced to a weak vortex Type 2 and 1 when an anti-vortex wall was installed. Moreover, the vortices became very unstable.
\end{abstract}

Keywords: hydropower plant, power intake, vortex, anti-vortex wall, vortex prevention, trash rack. 


\section{Introduction}

Power generation is one of the main targets in dam construction. To do so, many hydropower plants have been constructed and put into operation alongside dams all over the world. The formation of vortex at power intakes is an undesirable phenomenon that may cause a number of problems, such as decreasing the efficiency of turbines and their vibration, increasing hydraulic losses at the entrance of power intakes, entraining debris that may block the trash racks, entraining air into the power tunnel and reducing the working life of turbines [1]. The stronger the vortex the greater will be its negative effects on power intake performance.

Based on Alden Research Laboratory visual classification, vortices are divided into 6 types (Figure 1).

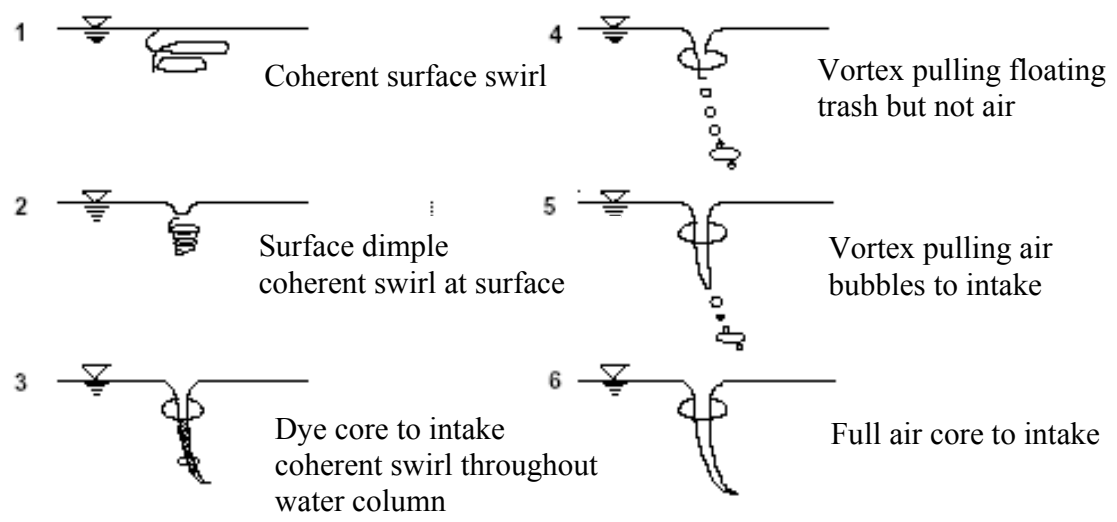

Figure 1: $\quad$ Different types of vortices [1].

Vortex Type 1 is observed as a weak rotation of flow at water surface. In vortex Type 2 in addition to water surface rotation a drop is also observed in water surface. In vortex Type 3 the rotation of flow is extended down to the intake itself. In vortex Type 4, debris is dragged into the intake. In vortex Type 5 some air bubbles are entrained from water surface and are transported down to the intake. In the strongest Type 6 vortex, a stable air core is formed in the centre of the vortex and air is entrained into the power tunnel steadily [1].

To prevent formation of an air core vortex, a minimum operating depth, called critical submerged depth ' $h_{c r}$ ' is recommended for the intakes. Submerged depth is defined as the distance between water surface and the axis of the intake (Figure 2). Many researchers have tried to find a relationship for $h_{c r}$ based on flow parameters such as the intake Froude number defined as: $F r=\frac{V}{\sqrt{g D}}$ where $V$ is intake velocity, $g$ is gravitational acceleration and $D$ is the power tunnel diameter (Berge 1966, Gordon 1970, Reddy and Pickford 1972, 
Amphlett 1976, Chang 1977) [2-4, 11, 12]. However, since many factors such as the reservoir geometry affect the strength of vortices these relationships are not very accurate and are valid within their data limits and experimental setups. Therefore in design of power intakes, especially for large dams, physical model study is required.

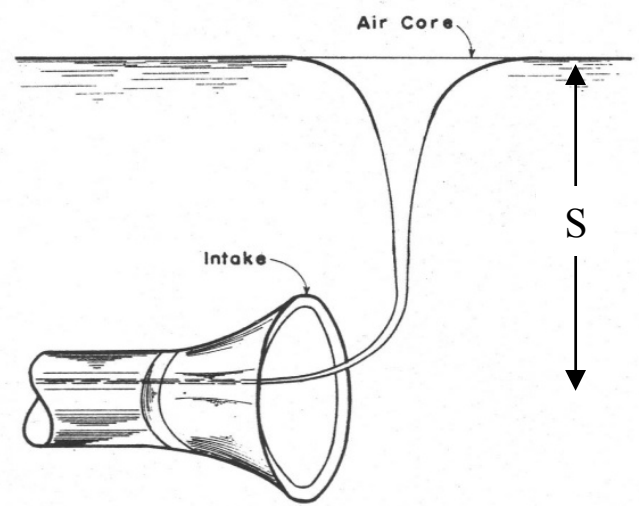

Figure 2: Formation of an air core vortex at the intake.

Critical submerged depth can be determined in a physical model. It should be noticed that since the operating level of the power intake should not be reduced below the critical submerged depth, the volume of water in this region can not be used for power generation. Therefore increasing the submerged depth of the intake for prevention of vortex formation may not always be an economical solution. On the other hand, construction of deeper intakes may be more expensive.

A strategy for preventing vortex formation or in another word decreasing the critical submerged depth is to employ anti-vortex devices. Considering the factors which affect vortex strength, it can be concluded that vortex formation can be prevented or its strength can be reduced if there is a disturbance and an increase in flow resistance along the vortex path. Knauss [1] introduced various anti-vortex devices for intakes. These devices include: i) Vertical walls on top of the intake which induce friction on vortices and reduce their strength, ii) half cylinder walls in front of the intakes which cuts the vortex path and cause additional resistance to flow rotation iii) floating plates at reservoir water surface, which prevents vortex rotation due to friction. Since this device is floating on water surface it can adjust itself above the power intake at any water surface elevation, and iv) horizontal plates installed on top of the intakes This device though is fixed above the intake, cuts the vortex path and prevents its rotation. (Figure 3).

In the present work formation of vortices was studied on power intakes of Godar-e-Lander Dam. To reduce the minimum operating water level of the reservoir, performance of anti-vortex walls were examined on the intakes. 


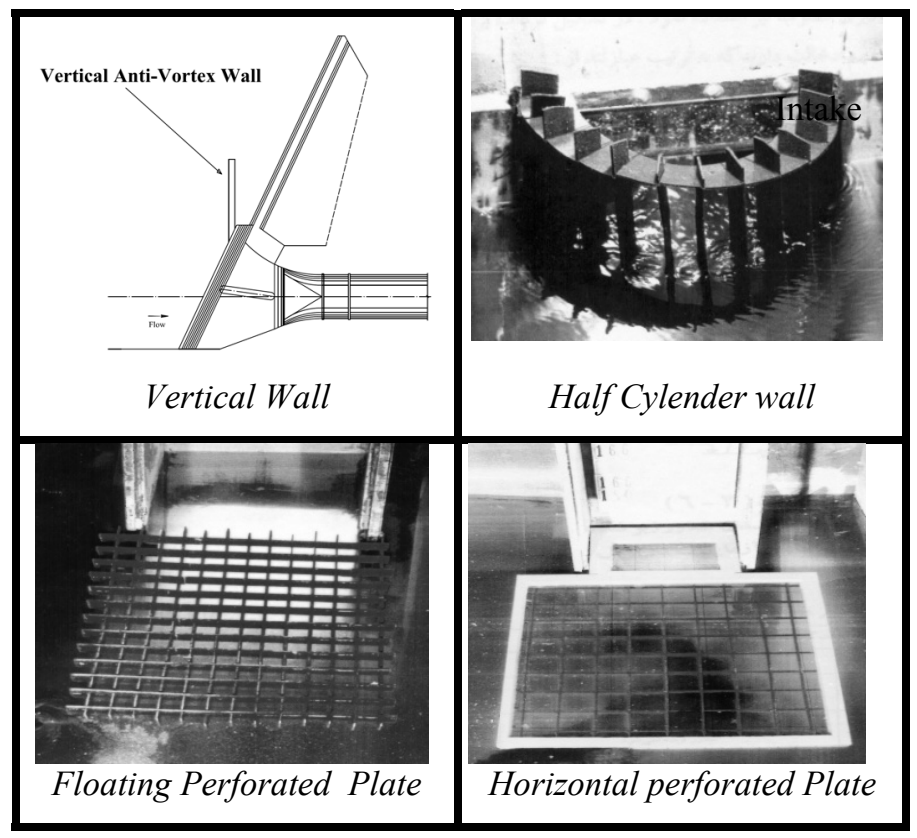

Figure 3: Few types of anti-vortex devices used at horizontal intakes (courtesy of Water Research Institute, Tehran, Iran).

In additional experiments the effect of trash rack and spillway operation simultaneously with the power intakes on type of vortices was studied at different reservoir levels.

\section{Experimental setup}

Godar-e-Lander is rock fill dam $170 \mathrm{~m}$ high. Four power tunnels with $10 \mathrm{~m}$ diameter were constructed to supply the 8 power units (Figure 4). Design discharge of each intake was $375 \mathrm{~m}^{3} / \mathrm{s}$. Elevation of intake axis was $340.98 \mathrm{~m}$ above the sea level (masl). Maximum and minimum reservoir operation level was designed at 372 masl and 363 masl respectively.

As a part of design, a 1:66.67 scale model of the dam was constructed in Water Research Institute Laboratory in Tehran. The hydraulic model of Godar-eLander Dam included: dam body, the reservoir, spillways, power intakes and a part of their downstream tunnels (Figure 5).

To include the effect of reservoir geometry on inlet flow pattern, an extension of $933 \mathrm{~m}$ of the reservoir upstream of the dam body and width of $667 \mathrm{~m}$ along the dam axis in prototype scale was constructed in the model. To be able to see the flow pattern at power intakes the reservoir walls and power intakes and tunnels were made from clear Perspex.

Standard orifice plates installed downstream of each power tunnel in the model were used for discharge measurement. A point gauge with $0.1 \mathrm{~mm}$ 
accurate was also used to measure elevation of water surface in the reservoir. To distinguish the vortex type in each test, light colorful objects were released in the flow.

This model study was used to collect hydraulic design data for the anti-vortex wall. The hydraulic information obtained from the model study included: type of vortices, vortex stability in various alternatives of anti-vortex walls.

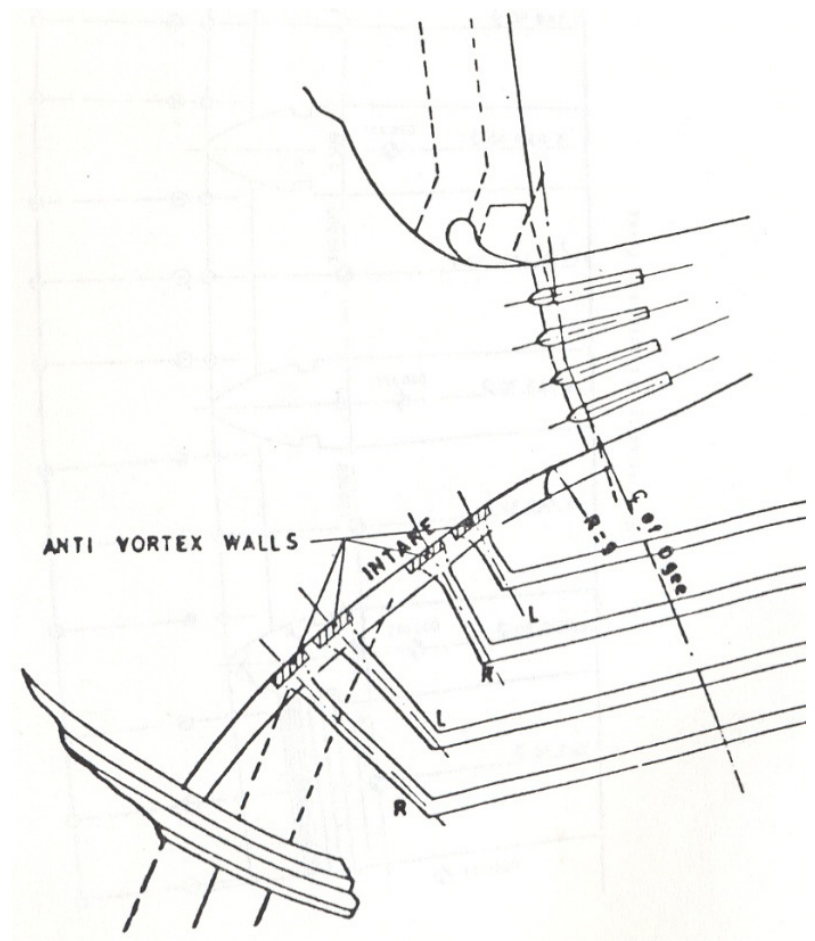

Figure 4: $\quad$ Plan view of power intakes and spillways.

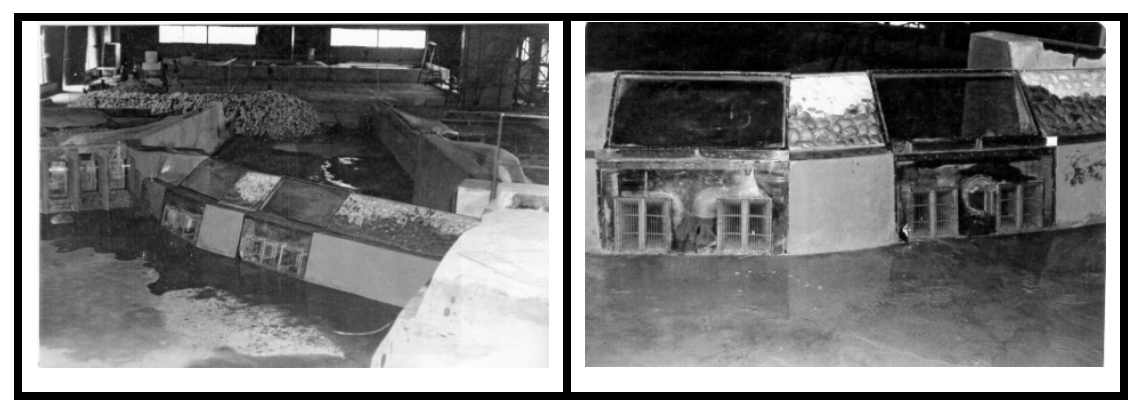

Figure 5: $\quad$ 1:66.67 scale model of the Godar-e-Lander Dam. 


\section{Model results}

Model studies showed that with operation of the intakes, at reservoir level of 367.5 masl that is $4.5 \mathrm{~m}$ above the designed minimum operation water level, stable vortex Type 4 formed. These tests were repeated with installation of trash rack on intakes and different combinations of intakes operation with similar results (Table 1). It was also observed that operation of the spillways simultaneously with the power intakes reduces the vortices strength by inducing turbulence in the reservoir. Additional tests showed that, since the vortex location was closer to the intake head wall at elevations below 365.5 masl, the vortex type reduced one level (Table 1 and Figure 6) $[5,6]$.

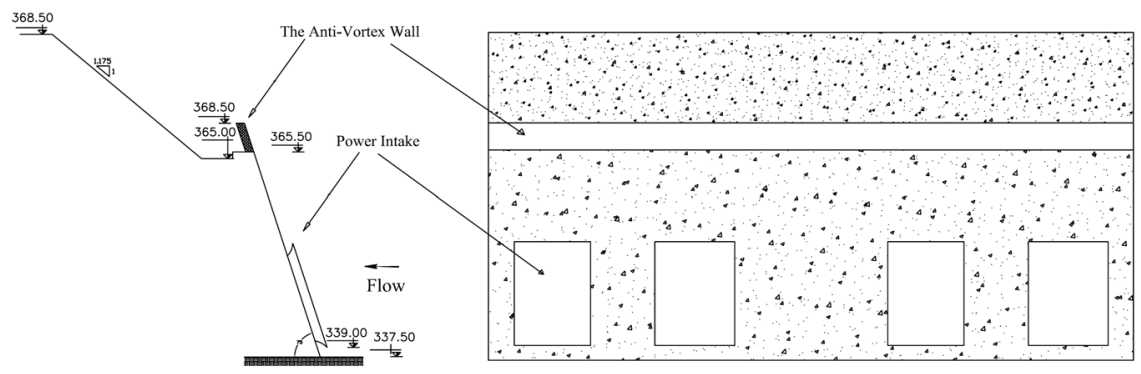

Figure 6: Side and front view of dam, power intake location and anti-vortex wall.

Owing to viscous effects in small scale models, strengths of vortices may be underestimated and therefore stronger air core vortices may form in the prototype. Considering negative consequences of vortex formation and air entrainment at power intakes, design of an anti-vortex wall was proposed to enable the dam operators to use the power units until the designed minimum water level of 363 masl.

In hydropower tunnels air should not be drawn into the intakes. This corresponds to vortex Type 5 and 6 . To evaluate the performance of the antivortex wall and considering the scale effects it was decided not to have vortices stronger than Type 2 in the model. This is especially acceptable since the cost of constructing anti-vortex walls is not high.

A wall was installed in the model at elevation 365.5 masl above each intake on top of the intake head wall and with the same slope (Figure 6). The top elevation of this anti-vortex wall was selected 368.5 masl which is the height above it no vortex was observed (see Table 1).

Different combinations for operation of intakes were tested at 3 reservoir surface elevations of 363 masl, 367.5 masl and 372 masl and 2 discharges for spillway operation and formation of vortices was monitored.

The results of these tests showed that the strongest vortex with the presence of the anti-vortex wall was Type 2 at elevation 367.5 masl. The vortices with the presence of wall were also very unstable (Table 1). These results showed the successful performance of the anti-vortex wall. 
Table 1: $\quad$ Summary of results on vortex formation and the performance of an anti-vortex wall at different conditions.

\begin{tabular}{|c|c|c|c|c|c|c|}
\hline $\begin{array}{c}\text { Reservoir } \\
\text { Level } \\
\text { (masl) }\end{array}$ & $\begin{array}{c}\text { Discharge } \\
\text { of } \\
\text { Spillway } \\
\left(\mathrm{m}^{3} / \mathrm{s}\right)\end{array}$ & Trash rack & $\begin{array}{l}\text { Number } \\
\text { of Active } \\
\text { Intakes }\end{array}$ & $\begin{array}{c}\text { Anti- } \\
\text { Vortex } \\
\text { Wall }\end{array}$ & $\begin{array}{c}\text { The more } \\
\text { Strength } \\
\text { Type of } \\
\text { Vortices }\end{array}$ & Stability \\
\hline 372 & Closed & No Trash rack & 1,2 & No wall & No Vortex & No Vortex \\
\hline 367.5 & Closed & No Trash rack & 1,2 & No wall & 4 & Stable \\
\hline 363 & Closed & No Trash rack & 1,2 & No wall & 3 & Stable \\
\hline 367.5 & 2500 & No Trash rack & 1 & No wall & 2 & Stable \\
\hline 367.5 & 2500 & No Trash rack & 1,2 & No wall & 2 & Stable \\
\hline 367.5 & Closed & No Trash rack & $1,2,3,4$ & No wall & 3 & Stable \\
\hline 367.5 & 2500 & No Trash rack & $1,2,3,4$ & No wall & 2 & Unstable \\
\hline 367.5 & 5000 & No Trash rack & $1,2,3,4$ & No wall & No Vortex & No Vortex \\
\hline 372 & Closed & Trash rack & 1,2 & No wall & No Vortex & No Vortex \\
\hline 367.5 & Closed & Trash rack & 1,2 & No wall & 4 & Stable \\
\hline 363 & Closed & Trash rack & 1,2 & No wall & 3 & Stable \\
\hline 367.5 & 2500 & Trash rack & 1 & No wall & 2 & Stable \\
\hline 367.5 & 2500 & Trash rack & 1,2 & No wall & 2 & Stable \\
\hline 367.5 & Closed & Trash rack & $1,2,3,4$ & No wall & 3 & Stable \\
\hline 367.5 & 2500 & Trash rack & $1,2,3,4$ & No wall & 2 & Unstable \\
\hline 367.5 & 5000 & Trash rack & $1,2,3,4$ & No wall & No Vortex & No Vortex \\
\hline 372 & Closed & Trash rack & 1,2 & yes & No Vortex & No Vortex \\
\hline
\end{tabular}


Table 1: $\quad$ Continued.

\begin{tabular}{|c|c|c|c|c|c|c|}
\hline $\begin{array}{c}\text { Reservoir } \\
\text { Level } \\
(\mathbf{m a s l})\end{array}$ & $\begin{array}{c}\text { Discharge } \\
\text { of } \\
\text { Spillway } \\
\left(\mathrm{m}^{3} / \mathrm{s}\right)\end{array}$ & \multicolumn{2}{c}{ Trash rack } & \multicolumn{1}{c}{$\begin{array}{c}\text { Number } \\
\text { of Active } \\
\text { Intakes }\end{array}$} & \multicolumn{1}{c|}{$\begin{array}{c}\text { Anti- } \\
\text { Vortex } \\
\text { Wall }\end{array}$} & \multicolumn{2}{c|}{$\begin{array}{c}\text { The more } \\
\text { Strength } \\
\text { Type of } \\
\text { Vortices }\end{array}$} & Stability \\
\hline 367.5 & Closed & Trash rack & 1,2 & yes & 2 & Unstable \\
\hline 363 & Closed & Trash rack & 1,2 & yes & 1 & Unstable \\
\hline 367.5 & 2500 & Trash rack & 1 & yes & No Vortex & No Vortex \\
\hline 367.5 & 2500 & Trash rack & 1,2 & yes & No Vortex & No Vortex \\
\hline 367.5 & Closed & Trash rack & $1,2,3,4$ & yes & 2 & Unstable \\
\hline 367.5 & 2500 & Trash rack & $1,2,3,4$ & yes & 1 & Unstable \\
\hline 367.5 & 5000 & Trash rack & $1,2,3,4$ & yes & No Vortex & No Vortex \\
\hline
\end{tabular}

\section{Summary and conclusions}

Formation of vortices at power intakes is an undesirable phenomenon, which cause number of problems. Stronger vortices have more negative effects on performance of a hydropower plant. Godar-e-Lander Dam and Hydropower Plant is placed in west of Iran. It is a rock fill dam with $170 \mathrm{~m}$ height from the foundation and a hydropower plant with the capacity of $2000 \mathrm{MW}$. In physical model study it was found that vortices of Type 4 were formed at the intakes at depths more than the minimum designed reservoir water level. Owing to scale effects stronger air core vortices may form in the prototype. Experiments also showed that operation of spillways has a great effect on reducing or eliminating vortices. It was also observed that trash rack effect on reducing type of vortices was negligible. To reduce the strength of vortices anti vortex walls were installed on top of each intake head wall and with the same slope. In fact the intake head wall was extended an extra $3 \mathrm{~m}$. Results of experiments showed that type of vortices reduced from Type 4 to Types 2 and 1 when anti-vortex walls were installed. Moreover vortices became very unstable when anti-vortex walls were present. The anti-vortex wall was then recommended as a cheap method to prevent vortex formation in the prototype.

\section{Acknowledgement}

The authors would like to thank Water Research Institute, Tehran, Iran for their permission in using the model data. 


\section{References}

[1] Knauss, J, "Swirling Flow Problems at intakes", Balkema, 1987.

[2] Gordon, J.L, "Vortices at Intakes", Water Power, 1970.

[3] Reddy, Y.R. \& Pickford, J.A., "Vortices at Intake in Conventional Sumps", Water Power, No.3, 1972.

[4] Amphlet, M.B, "Air Entraining Vortices at Horizontal Intake", HRC Wallingford Rep., No .OD/7,1976

[5] Sarkardeh, H, Safavi, K \& Karaminejad, R "Experimental study of vertical anti-vortex wall at power intakes of Karun III dam", 2nd IJREW on Hydraulic Structures, Italy, 2008.

[6] Sarkardeh, H, Zarrati, A.R \& Roshan, R "Effect of intake head wall and trash rack on type and strength of vortices", Journal of Hydraulic Research, Submitted for publication, 2008.

[7] Lugt, H.J, "Vortex Flow in Nature and Technology", John Wiley \& Sons, 1983.

[8] Hecker, G.E, "Model-Prototype Comparison of Free Surface Vortices", Journal of Hydraulic Engineering, Vol.107, No.10, pp 1243-1259, 1981.

[9] Anwar, H.O., Weller, J.A \& Amphlett M.B, "Similarity of Free Vortex at Horizontal Intake”, Journal of Hydraulic Research,No.2,pp 95-105, 1978

[10] Jain, A.K, Raju, K.G.R \& Grade, R.J, "Vortex Formation at Vertical Pipe Intake", Journal of Hydraulic Engineering, Vol.100, No.10, pp 1427-1445, 1987.

[11] Berge, J.P. (1966). A Study of Vortex Formation and Other Abnormal Flow in a Tank with and without a Free Surface. La Houille Blanche, No.1.

[12] Chang, E. (1977). Review of Literature on Drain Vortices in Cylindrical Tanks. BHRA Report, TN.1342, March. 